\title{
A Clinical and Budgetary Impact Analysis of Introducing Sugammadex for Routine Reversal of Neuromuscular Blockade in a Hypothetical Cohort in the US
}

\author{
Yiling Jiang · Lori D. Bash · Leif Saager
}

Received: December 10, 2020 / Accepted: March 10, 2021 / Published online: April 19, 2021

(C) The Author(s) 2021

\section{ABSTRACT}

Introduction: Sugammadex rapidly reverses the effects of rocuronium- and vecuronium-induced neuromuscular blockade (NMB), offering a more complete and predictable $\mathrm{NMB}$ recovery than cholinesterase inhibitors. Despite clinical benefits, cost pressures on hospital budgets influence the choice of the NMB reversal method. This study evaluated clinical and healthcare system payer's budget impacts associated with sugammadex in the US for routine reversal of moderate or deep rocuronium- or vecuronium-induced $\mathrm{NMB}$ in adults undergoing surgery.

Methods: A 1-year decision analytic model was constructed reflecting a set of procedures using rocuronium or vecuronium that resulted in moderate or deep NMB at the end of surgery.

\section{Y. Jiang $(\bowtie)$}

Center for Observational and Real-world Evidence (CORE), Merck Sharp \& Dohme (UK) Ltd., 120

Moorgate, London EC2Y 9AL, UK

e-mail: yiling.jiang1@msd.com

L. D. Bash

Center for Observational and Real-world Evidence (CORE), Merck \& Co., Inc., Kenilworth, NJ, USA

\section{Saager}

Department of Anesthesiology, University of

Michigan, Ann Arbor, MI, USA

L. Saager

Klinik fuer Anaesthesiologie Universitaetsmedizin

Goettingen, Goettingen, Germany
Two scenarios were considered for a hypothetical cohort of 100,000 patients: without sugammadex versus with sugammadex. Comparators included neostigmine (+glycopyrrolate) and no neuromuscular blocking agents (NMBAs). Total costs (in 2019 US dollars) to a healthcare system [net of costs of reversal agents and overall cost offsets via reduction in postoperative pulmonary complications (PPC)] were compared.

Results: A total of 9971 surgical procedures utilized rocuronium or vecuronium, resulting in moderate (91.0\% of cases) or deep $(9.0 \%)$ blockade at the end of surgeries. In the with sugammadex scenario, sugammadex replaced neostigmine in 4156 of 9585 procedures versus the without sugammadex scenario that used only neostigmine for NMB reversal. Introducing sugammadex reduced PPC events by $12 \%$ (58 cases) among the modeled procedures, leading to a budget impact of $-\$ 3,079,703$ (-\$309 per modeled procedure, or a $10.9 \%$ reduction in total costs). The results did not vary qualitatively in one-way sensitivity analyses. Conclusions: The additional costs of sugammadex for the reversal of rocuronium- or vecuronium-induced $\mathrm{NMB}$ could be offset by improved outcomes (i.e., reduced PPC events), and potentially lead to overall healthcare budgetary savings versus reversal with neostigmine or spontaneous recovery. This study provides insights into savings that can be obtained beyond the anesthesia budget, reducing the broader clinical and budgetary burden on the hospital. 
Keywords: Bridion; Budget impact; Cost; Neuromuscular blockade; complications; Sugammadex

\section{Key Summary Points}

Why carry out this study?

Neuromuscular blockade (NMB) is a key component of general anesthesia, and reversal agents are often used to allow a more rapid recovery following surgery.

Sugammadex rapidly and predictably reverses the effects of rocuronium- and vecuronium-induced NMB compared with other reversal agents, but despite clinical benefits, cost often influences choice of NMB reversal method.

What did the study ask?/What was the hypothesis of the study?

This study aimed to quantify the clinical and budgetary impact of introducing sugammadex for the routine reversal of moderate or deep NMB induced by rocuronium or vecuronium in adults undergoing surgery in the US. It was hypothesised that improved clinical outcomes through the use of sugammadex rather than neostigmine may reduce overall costs of care.

\section{What were the study outcomes/conclusions?}

The additional cost associated with sugammadex for the reversal of rocuronium- or vecuronium-induced NMB may be offset by improved clinical outcomes and budgetary savings versus reversal with neostigmine or spontaneous recovery.

\section{What was learned from the study?}

This study provides insights into savings that may be achieved beyond the anesthesia budget, reducing the broader hospital clinical and budgetary burden.

\section{DIGITAL FEATURES}

This article is published with digital features, including a summary slide, to facilitate understanding of the article. To view digital features for this article go to https://doi.org/10.6084/ m9.figshare.14179364.

\section{INTRODUCTION}

Muscle paralysis, or neuromuscular blockade (NMB), is a key component of balanced general anesthesia, facilitating tracheal intubation, mechanical ventilation, and muscle relaxation to optimize surgical conditions $[1,2]$. Two of the most commonly used neuromuscular blocking agents (NMBAs) in the US are rocuronium and vecuronium. Differences in the onset, depth, and duration of action among NMBAs are the main factors influencing the choice of agent for surgical procedures.

To allow for extubation of the patient and spontaneous breathing at the end of general anesthesia, patients may either be allowed to spontaneously recover neuromuscular function, or, more commonly, they may be administered a reversal agent for more rapid recovery. Pharmacologic reversal of $\mathrm{NMB}$ allows patients to regain normal breathing as quickly and reliably as possible, as well as regain protective airway, swallow and cough reflexes [3].

Frequently, residual NMB persists into the early postoperative recovery period, despite NMB monitoring or reversal $[4,5]$. Real-world studies in those who received reversal with the cholinesterase inhibitor, neostigmine, have shown a concerningly high incidence of residual NMB (based on evaluation by quantitative acceleromyography with train-of-four [TOF] stimulation), in up to $65 \%$ of patients during tracheal extubation [6-8]. Residual NMB and associated muscle weakness during the vulnerable postoperative period [9] can lead to impairment in breathing, upper airway patency, protective airway reflexes, swallowing, coughing, and associated complications [10, 11]. Residual blockade has been observed to prolong time spent in both the operating room and the 
post-anesthesia care unit; residual blockade is also associated with an increase in unplanned admittance to the intensive care unit following surgery [12]. Hence, the attendant risks of postoperative morbidity [5] and mortality [13], as well as the humanistic [14, 15] and cost consequences of residual NMB $[16,17]$, point to the need for improved NMB reversal.

Sugammadex (Bridion $^{\circledR}$, Merck Sharp \& Dohme Corp., a subsidiary of Merck \& Co., Inc., Kenilworth, NJ, USA) is a modified $\gamma$-cyclodextrin designed specifically to reverse the effects of rocuronium- and vecuronium-induced NMB by encapsulation [18, 19]. Meta-analytic evidence has confirmed that, compared with neostigmine, sugammadex 2 or $4 \mathrm{mg} / \mathrm{kg}$ rapidly and effectively reverses moderate and deep NMB induced by rocuronium or vecuronium $[17,20,21]$. Sugammadex received approval from the US Food and Drug Administration in December 2015 for use in adults.

Notwithstanding the endorsements of the clinical and safety benefits of sugammadex $[17,20-22]$, agents introduced to the already resource-intensive intraoperative and postoperative hospital settings receive high levels of economic scrutiny by payers and formulary committees [23]. Therefore, evidence of broader benefits of NMB reversal should be assessed to address economic concerns and identify best clinical practice [24, 25].

This study evaluated the clinical and budget impact of introducing sugammadex for the routine reversal of moderate or deep $\mathrm{NMB}$ induced by rocuronium or vecuronium in adults undergoing surgery in the US.

\section{METHODS}

\section{Model Overview}

A decision analytic model was constructed reflecting a set of procedures that used rocuronium or vecuronium as NMBA intraoperatively, resulting in moderate or deep $\mathrm{NMB}$ at the end of the procedure, that is, procedures that are eligible to receive sugammadex (Fig. 1). The analysis did not stratify by risk factors, but rather it represented an average patient risk profile that is consistent with a broad inpatient surgical population, similar to that reported in Kheterpal et al. [17]. This was a hypothetical modeling study with no real patients involved, and hence no ethics approval or consent was required or requested. Assumptions for the model were derived from existing published study data as referenced within the text.

The model comprised three analytic modules: the population module, the market share module, and the economic module. The population module estimated the number of procedures that used rocuronium or vecuronium as NMBA and had achieved moderate or deep $\mathrm{NMB}$ at the end of the procedure. The market share module estimated the number of patients who received sugammadex, neostigmine, or no reversal agent. The economic module then estimated the costs of reversal agents and costs associated with the management of postoperative pulmonary complications (PPC).

The model considered two scenarios based on different market shares of, or proportions of, procedures utilizing sugammadex, neostigmine (administered with glycopyrrolate to minimize the risk of muscarinic adverse events), or no NMBA reversal agent (Fig. 1). Data inputs for the market share and economic modules were specific to each of the two scenarios. The scenario with the availability of sugammadex was compared with the scenario without the availability of sugammadex. For neostigmine, the product label specifies administration for reversal of moderate blockade only. In the case of deep blockade, it was assumed that the anesthesiologist would wait until the patient had spontaneously recovered to moderate blockade before administering neostigmine (assuming that neostigmine was used consistent with its product indication, and not at the end of surgery while the patient was still under deep NMB).

For both scenarios, the model estimated total costs in terms of the costs for NMB reversal agents and the costs of managing PPCs. The budget impact was calculated as the difference in total costs between the two scenarios.

The model time horizon was assumed to be 1 year. Costs were expressed in 2019 US dollars, and estimated from the perspective of a 


\begin{tabular}{|c|c|}
\hline $\begin{array}{l}\text { Total num } \\
\text { procec } \\
\text { geogr }\end{array}$ & $\begin{array}{r}\text { Proportio } \\
\text { using } \\
\text { geog }\end{array}$ \\
\hline 000 & $19.0 \%$ \\
\hline
\end{tabular}

\begin{tabular}{|c|c|c|c|c|c|c|}
\hline $\operatorname{Cost}_{2}=$ & $\begin{array}{l}\text { Size of the target } \\
\text { population }\end{array}$ & $x$ & Market share & $\mathrm{x}$ & $\begin{array}{l}\text { Cost of medications } \\
\text { and PPC }\end{array}$ & $\begin{array}{l}\text { Scenario: } \\
\text { With sugammadex }\end{array}$ \\
\hline 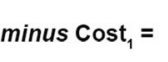 & $\begin{array}{l}\text { Size of the target } \\
\text { population }\end{array}$ & $x$ & Market share & $x$ & $\begin{array}{l}\text { Cost of medications } \\
\text { and PPC }\end{array}$ & $\begin{array}{c}\text { Scenario: } \\
\text { Without sugammadex }\end{array}$ \\
\hline
\end{tabular}

Budget impact

Fig. 1 Model schematics, number of procedures (total and modeled), and market shares of NMB reversal agents for scenarios, without sugammadex and with sugammadex (\%;

healthcare system payer. Costs were not discounted due to the short time horizon.

The analytic model was developed in Microsoft ${ }^{\circledR}$ Excel $^{\circledR} 365$ (Microsoft, Redmond, WA, USA) and complied with recommendations of the Academy of Managed Care Pharmacy Format for Formulary Submissions [26] and the International Society for Pharmacoeconomics and Outcomes Research Principles of Good n). $N M B$ neuromuscular blockade, $N M B A$ neuromuscular blocking agent

Practice for Budget Impact Analysis [24]. In addition, reporting followed the Consolidated Health Economic Evaluation Reporting Standards Good Reporting Practices [27]. This study did not require ethics committee approval as it used data from previous sources. 


\section{Size of the Target Population and Market Shares}

The target population in the model was based on an overall hypothetical cohort of 100,000 adult patients (aged $\geq 18$ years) within a hypothetical geographic region that is covered by a medium-to-large integrated delivery system. A proportion of these patients underwent procedures that utilized rocuronium or vecuronium as a NMBA for achieving either moderate or deep NMB during the procedure. The number of procedures using NMBA was estimated using the total number of surgical procedures multiplied by the proportion of procedures which were to receive $\mathrm{NMB}$ reversal agents (19.0\%; Fig. 1). The number of procedures using NMBA were then stratified by the type of NMBA used (rocuronium, $75.8 \%$, or vecuronium, $6.1 \%$ ) and then further stratified by the depth of NMB (moderate, 58.4\%, or deep, 5.8\%; Fig. 1). Moderate NMB was defined as spontaneous recovery reaching the reappearance of the second twitch in response to TOF stimulation, and deep NMB was defined as a twitch response of 1-2 post-tetanic counts, and no twitch responses to TOF stimulation. The estimates of procedures using NMBA were based on unpublished market research, which covered 74.4 million surgical procedures in the US between December 2016 and November 2017, based on the IQVIA Charge Master database (Merck \& Co., Inc.; data on file). This database covers a random sample of more than 350 non-governmental acute care hospitals, captures both outpatient and inpatient hospital encounters, and includes all payer types (Medicare, Medicaid, commercial, and others). The estimates of the depth of NMB were based on an unpublished tracker survey to monitor NMB reversal agent landscape, involving 193 anesthesiologists and certified registered nurse anesthetists from geographies across the US, including both academic medical centers and community hospitals (Merck \& Co., Inc.; data on file). All market share assumptions presented in Fig. 1 were based on the aforementioned US survey (Merck \& Co., Inc.; data on file).

\section{Clinical Outcomes}

The clinical outcome considered in the model was the number of PPC events, a composite endpoint which included pneumonia, respiratory failure, and/or other major pulmonary complications, components which were consistent with those previously defined among standard definitions of perioperative outcomes measures [28], and further refined to be related more conservatively to NMB management, as described by Kheterpal et al. [17]. Outcomes were based on an analysis of real-world US data from the Multicenter Perioperative Outcomes Group consortium by Kheterpal et al. (2020) (the STRONGER study) [17], and similar to those described elsewhere $[29,30]$. The STRONGER study represents 45,712 patients treated between January 2014 and August 2018. This US multicenter study assessed the impact of real-world routine use of NMB and NMB reversal agents in noncardiac surgical inpatients who were not contraindicated for the treatment with sugammadex. More information on the STRONGER study has been reported in its primary publication [17].

The study had observed a PPC incidence rate of $4.8 \%$ among patients treated with neostigmine [17]. The adjusted risk ratio, from an ad hoc analysis of the Kheterpal study (which only reported an odds ratio of 0.70), using logistic regression models of PPC associated with sugammadex versus neostigmine of 0.71 (Merck \& Co., Inc.; data on file), was then applied to $4.8 \%$ to estimate the incidence of PPC associated with sugammadex use (3.4\%). This approach limits the impact of imbalanced covariates on the treatment effect, compared with using the crude incidence directly from the Kheterpal et al. study.

Patients not actively reversed pharmacologically (spontaneous reversal) were not evaluated in the Kheterpal et al. study [17]. Incomplete reversal can put patients at risk of incomplete neuromuscular recovery, and consequently impair pulmonary and respiratory muscle function [31]. Although rates of PPC may be higher among patients who undergo sponta- 
neous reversal compared with those who are pharmacologically reversed, for the purposes of this analysis, it was conservatively assumed that patients not treated with a reversal agent (spontaneously reversed) have the same risk (of PPC) as those reversed with neostigmine. We also assumed that the clinical outcomes were the same between moderate and deep blockade, as the STRONGER study did not differentiate and included all NMB depths [17].

\section{Costs}

\section{Costs of Reversal Agents}

For sugammadex, the average number of vials used was estimated based on the recommended dose by body weight and depth of blockade (a dose of $2 \mathrm{mg} / \mathrm{kg}$ and $4 \mathrm{mg} / \mathrm{kg}$ of sugammadex is recommended for moderate and deep NMB, respectively), assuming a single use of each vial, as specified in the product label [32] (Table 1). Patient body weight distribution in the US was estimated from the national reference data collected between 2011 and 2014, as reported by the US Centers for Disease Control and Prevention [33].

For neostigmine, a dose of $0.03 \mathrm{mg} / \mathrm{kg}$ is recommended for the reversal of rocuroniuminduced moderate $\mathrm{NMB}$, while a dose of $0.07 \mathrm{mg} / \mathrm{kg}$ is recommended for the reversal of vecuronium-induced moderate NMB (Table 1), both with the recommended maximum dose of $5 \mathrm{mg}[34,35]$. In the analysis, it was assumed that a 5-mg vial (the lowest dosage available in the US) would be used per procedure. Furthermore, as neostigmine is co-administered with an antimuscarinic agent [34], which is typically glycopyrrolate in the US, the cost of glycopyrrolate was considered within the total treatment cost for neostigmine for this analysis. Per the label, we assumed a dose of $0.2 \mathrm{mg}$ glycopyrrolate for each $1.0 \mathrm{mg}$ of neostigmine, up to a maximum dose of $1 \mathrm{mg}$ glycopyrrolate (Table 1). The model did not consider severely underweight or morbidly obese patients $[36,37]$. Unit prices (wholesale acquisition cost) of all medications were retrieved from AnalySource (June 2019 data; Table 1) [38].

\section{Costs of PPC Management}

The composite endpoint of PPC covered a range of ICD-9 and ICD-10 diagnostic codes as observed by Kheterpal et al. [17], with the unit cost for each ICD code obtained from the average charges reported in the HCUPnet database (Healthcare Cost and Utilization Project, 2015 data [39]; Table 2). These published costs were inflated to May 2019 costs (latest available data at the time of analysis) using the medical care consumer price index (series CUUR0000SAM; 2015 index $=446.752, \quad$ May 2019 index $=494.928$ ) obtained from the US Bureau of Labor Statistics [40]. The cost of PPC was estimated as the average cost of the included ICD codes [17] weighted by the corresponding incidence of each. The weighted average cost per episode of PPC was estimated at $\$ 57,902.69$ (Table 2).

\section{Analyses}

The base case analysis estimated, by scenario, the number of procedures and PPC events, costs of reversal agents and PPC, and total costs. The clinical and budget impact was calculated in terms of differences in total PPC events and costs between scenarios.

A one-way sensitivity analysis was conducted to explore the impact of parametric uncertainty on the base case result, by varying key parameters between a plausible range of $\pm 25 \%$ to test the impact of parameters on results. The variables tested included: proportion of procedures using an NMB agent, sugammadex uptake rate in scenario 2, incidence of PPC, risk ratio of PPC for sugammadex versus neostigmine, costs of neostigmine and glycopyrrolate, and costs of PPC management.

\section{RESULTS}

\section{Base Case Results}

\section{Number of Procedures}

For a hypothetical target population of 100,000 adult patients (within a geographical region) undergoing a hospital surgical procedure, 


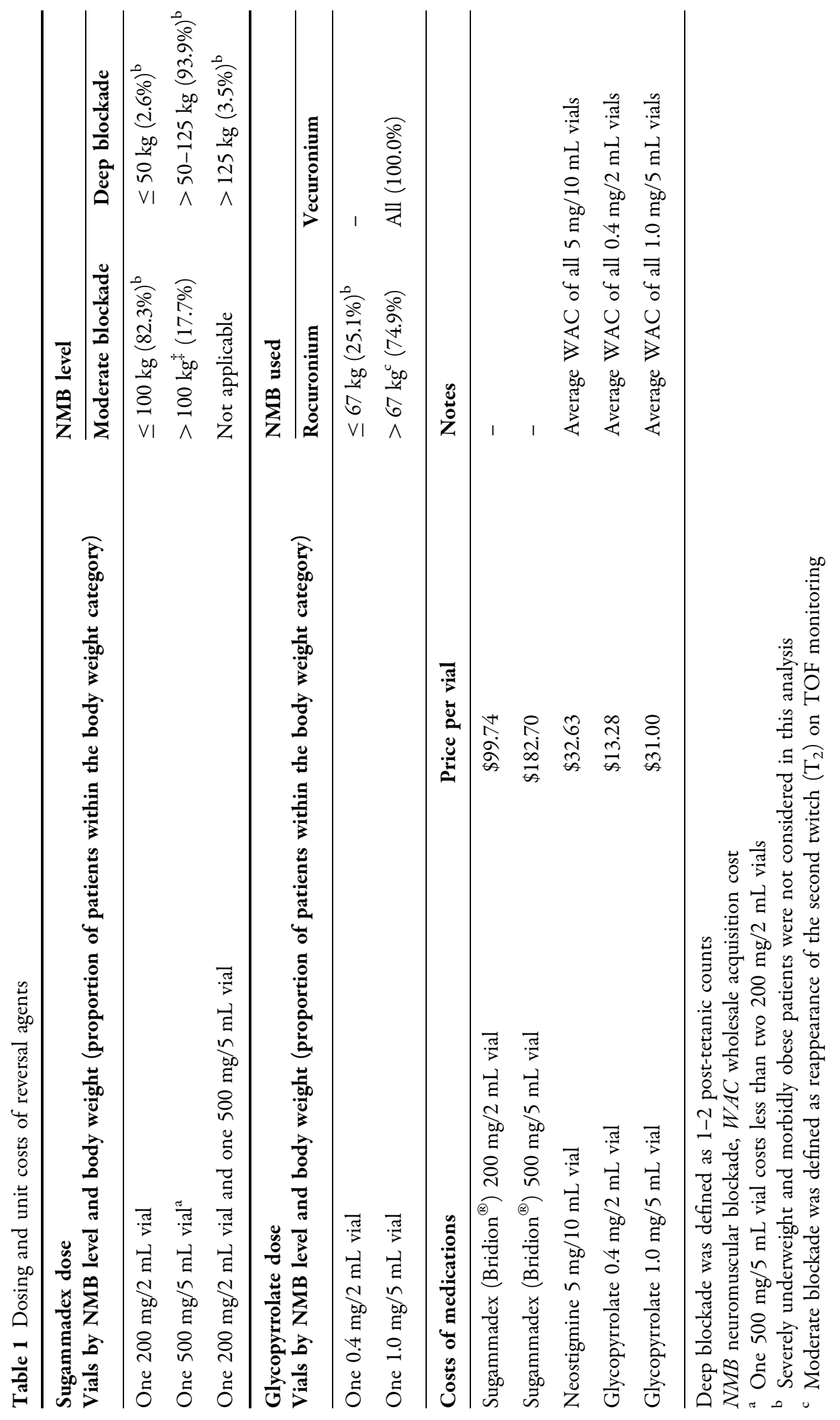


Table 2 Costs of postoperative pulmonary complications

\begin{tabular}{|c|c|c|c|c|c|c|}
\hline Category & ICD-9 & ICD-10 & Description & $\begin{array}{l}\text { Mean } \\
\text { hospital } \\
\text { charges } \\
\text { ( } 2015 \text { data) }\end{array}$ & $\begin{array}{l}\text { Mean } \\
\text { hospital } \\
\text { charges } \\
\text { (inflated to } \\
\text { May 2019) }\end{array}$ & $\begin{array}{l}\text { Proportion } \\
\text { of patients }\end{array}$ \\
\hline \multicolumn{3}{|c|}{ Weighted average } & & & $\$ 57,902.69$ & \\
\hline Pneumonia & 481 & $\mathrm{~J} 13$ & $\begin{array}{c}\text { Pneumococcal } \\
\text { pneumonia } \\
\text { (Streptococcus } \\
\text { pneumoniae) }\end{array}$ & $\$ 38,218.69$ & $\$ 42,340.05$ & $0.2 \%$ \\
\hline Pneumonia & 482.0 & $\mathrm{~J} 15.0$ & $\begin{array}{l}\text { Pneumonia due to } \\
\text { Klebsiella pneumoniae }\end{array}$ & $\$ 70,647.43$ & $\$ 78,265.78$ & $0.5 \%$ \\
\hline Pneumonia & 482.1 & $\mathrm{~J} 15.1$ & $\begin{array}{l}\text { Pneumonia due to } \\
\text { Pseudomonas }\end{array}$ & $\$ 75,667.27$ & $\$ 83,826.93$ & $0.8 \%$ \\
\hline Pneumonia & 482.30 & $\mathrm{~J} 15.4$ & $\begin{array}{l}\text { Pneumonia due to } \\
\text { Streptococcus, } \\
\text { unspecified }\end{array}$ & $\$ 35,635.46$ & $\$ 39,478.25$ & $0.2 \%$ \\
\hline Pneumonia & 482.40 & $\mathrm{~J} 15.20$ & $\begin{array}{l}\text { Pneumonia due to } \\
\text { Staphylococcus, } \\
\text { unspecified }\end{array}$ & $\$ 44,369.49$ & $\$ 49,154.13$ & $0.0 \%$ \\
\hline Pneumonia & 482.41 & $J 15.211$ & $\begin{array}{l}\text { Pneumonia due to } \\
\text { Staphylococcus aureus }\end{array}$ & $\$ 72,699.08$ & $\$ 80,538.66$ & $0.5 \%$ \\
\hline Pneumonia & 482.42 & $\mathrm{~J} 15.212$ & $\begin{array}{l}\text { Methicillin-resistant } \\
\text { pneumonia due to } \\
\text { Staphylococcus aureus }\end{array}$ & $\$ 76,141.87$ & $\$ 84,352.71$ & $0.6 \%$ \\
\hline Pneumonia & 482.82 & $\mathrm{~J} 15.5$ & $\begin{array}{l}\text { Pneumonia due to } \\
\text { Escherichia coli }\end{array}$ & $\$ 77,742.56$ & $\$ 86,126.02$ & $0.2 \%$ \\
\hline Pneumonia & 482.83 & J15.6 & $\begin{array}{l}\text { Pneumonia due to other } \\
\text { Gram-negative } \\
\text { bacteria }\end{array}$ & $\$ 44,131.51$ & $\$ 48,890.48$ & $0.6 \%$ \\
\hline Pneumonia & 482.89 & $\mathrm{~J} 15.8$ & $\begin{array}{l}\text { Pneumonia due to other } \\
\text { specified bacteria }\end{array}$ & $\$ 61,804.74$ & $\$ 68,469.53$ & $0.2 \%$ \\
\hline Pneumonia & 482.9 & $\mathrm{~J} 15.9$ & $\begin{array}{l}\text { Bacterial pneumonia, } \\
\text { unspecified }\end{array}$ & $\$ 32,654.95$ & $\$ 36,176.33$ & $0.5 \%$ \\
\hline Pneumonia & 486 & J18.9 & $\begin{array}{l}\text { Pneumonia, organism } \\
\text { unspecified }\end{array}$ & $\$ 33,581.89$ & $\$ 37,203.23$ & $28.2 \%$ \\
\hline Pneumonia & 483.8 & $\mathrm{~J} 16.8$ & $\begin{array}{l}\text { Pneumonia due to } \\
\text { another specified } \\
\text { organism }\end{array}$ & $\$ 62,470.44$ & $\$ 69,207.01$ & $0.2 \%$ \\
\hline Pneumonia & 484.6 & B 44.0 & $\begin{array}{l}\text { Pneumonia in } \\
\text { aspergillosis }^{\mathrm{a}}\end{array}$ & $\$ 54,230.56$ & $\$ 60,078.57$ & $0.0 \%$ \\
\hline Pneumonia & 485 & $\mathrm{~J} 18.0$ & $\begin{array}{l}\text { Bronchopneumonia, } \\
\text { organism unspecified }\end{array}$ & $\$ 33,462.42$ & $\$ 37,070.88$ & $0.2 \%$ \\
\hline
\end{tabular}


Table 2 continued

\begin{tabular}{|c|c|c|c|c|c|c|}
\hline Category & ICD-9 & ICD-10 & Description & $\begin{array}{l}\text { Mean } \\
\text { hospital } \\
\text { charges } \\
\text { (2015 data) }\end{array}$ & $\begin{array}{l}\text { Mean } \\
\text { hospital } \\
\text { charges } \\
\text { (inflated to } \\
\text { May 2019) }\end{array}$ & $\begin{array}{l}\text { Proportion } \\
\text { of patients }\end{array}$ \\
\hline Others & 507.0 & $\mathrm{~J} 69.0$ & $\begin{array}{l}\text { Pneumonitis due to } \\
\text { inhalation of food or } \\
\text { vomitus }\end{array}$ & $\$ 52,562.48$ & $\$ 58,230.61$ & $9.7 \%$ \\
\hline Others & 514 & $\mathrm{~J} 18.2$ & $\begin{array}{l}\text { Pulmonary congestion } \\
\text { and hypostasis }\end{array}$ & $\$ 30,314.54$ & $\$ 33,583.54$ & $2.3 \%$ \\
\hline $\begin{array}{l}\text { Respiratory } \\
\text { failure }\end{array}$ & 518.51 & $\mathrm{~J} 95.821$ or J96.00 & $\begin{array}{l}\text { Acute respiratory failure } \\
\text { following trauma and } \\
\text { surgery }\end{array}$ & $\$ 92,961.03$ & $\$ 102,985.59$ & $10.3 \%$ \\
\hline $\begin{array}{l}\text { Respiratory } \\
\text { failure }\end{array}$ & 518.52 & J95.1 or J95.2 & $\begin{array}{l}\text { Other pulmonary } \\
\text { insufficiency, not } \\
\text { elsewhere classified, } \\
\text { following trauma and } \\
\text { surgery }\end{array}$ & $\$ 110,752.65$ & $\$ 122,695.79$ & $3.3 \%$ \\
\hline $\begin{array}{l}\text { Respiratory } \\
\text { failure }\end{array}$ & 518.81 & $\mathrm{~J} 96.00$ or $\mathrm{J} 96.90$ & Respiratory failure & $\$ 68,105.51$ & $\$ 75,449.74$ & $14.1 \%$ \\
\hline $\begin{array}{l}\text { Respiratory } \\
\text { failure }\end{array}$ & 518.82 & $\mathrm{~J} 80$ & $\begin{array}{l}\text { Other pulmonary } \\
\text { insufficiency, not } \\
\text { elsewhere classified }\end{array}$ & $\$ 37,712.64$ & $\$ 41,779.43$ & $2.7 \%$ \\
\hline $\begin{array}{l}\text { Respiratory } \\
\text { failure }\end{array}$ & 518.84 & J96.20 & $\begin{array}{l}\text { Acute and chronic } \\
\text { respiratory failure }\end{array}$ & $\$ 65,138.61$ & $\$ 72,162.91$ & $0.6 \%$ \\
\hline Others & 997.39 & $\begin{array}{l}\text { J95.859 or J95.88 or } \\
\text { J95.89 }\end{array}$ & $\begin{array}{l}\text { Other respiratory } \\
\text { complications }\end{array}$ & $\$ 52,341.59$ & $\$ 57,985.91$ & $4.7 \%$ \\
\hline Others & 415.11 & $\begin{array}{l}\text { T80.0XXA or T81.718A } \\
\text { or T81.72XA or } \\
\text { T82.817A or } \\
\text { T82.818A or } \mathrm{I} 26.90 \text { or } \\
\text { I26.99 }\end{array}$ & $\begin{array}{l}\text { Iatrogenic pulmonary } \\
\text { embolism and } \\
\text { infarction }\end{array}$ & $\$ 38,389.07$ & $\$ 42,528.80$ & $14.4 \%$ \\
\hline Others & 512.1 & J95.811 & $\begin{array}{l}\text { Iatrogenic } \\
\text { pneumothorax }\end{array}$ & $\$ 38,746.92$ & $\$ 42,925.23$ & $5.0 \%$ \\
\hline
\end{tabular}

a Data not available, assumed to the average cost of other ICD codes within pneumonia category

ICD International Classification of Diseases 


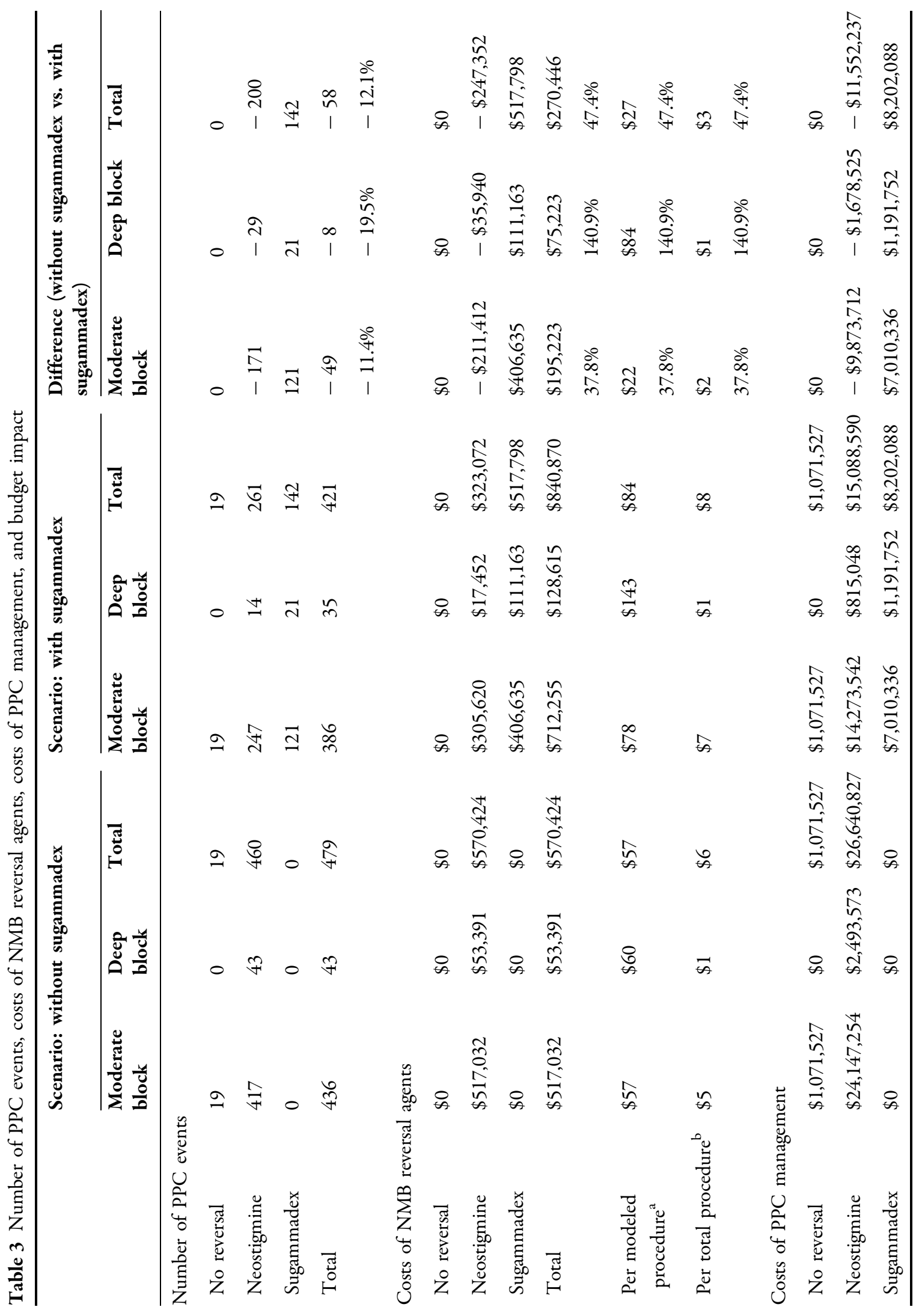




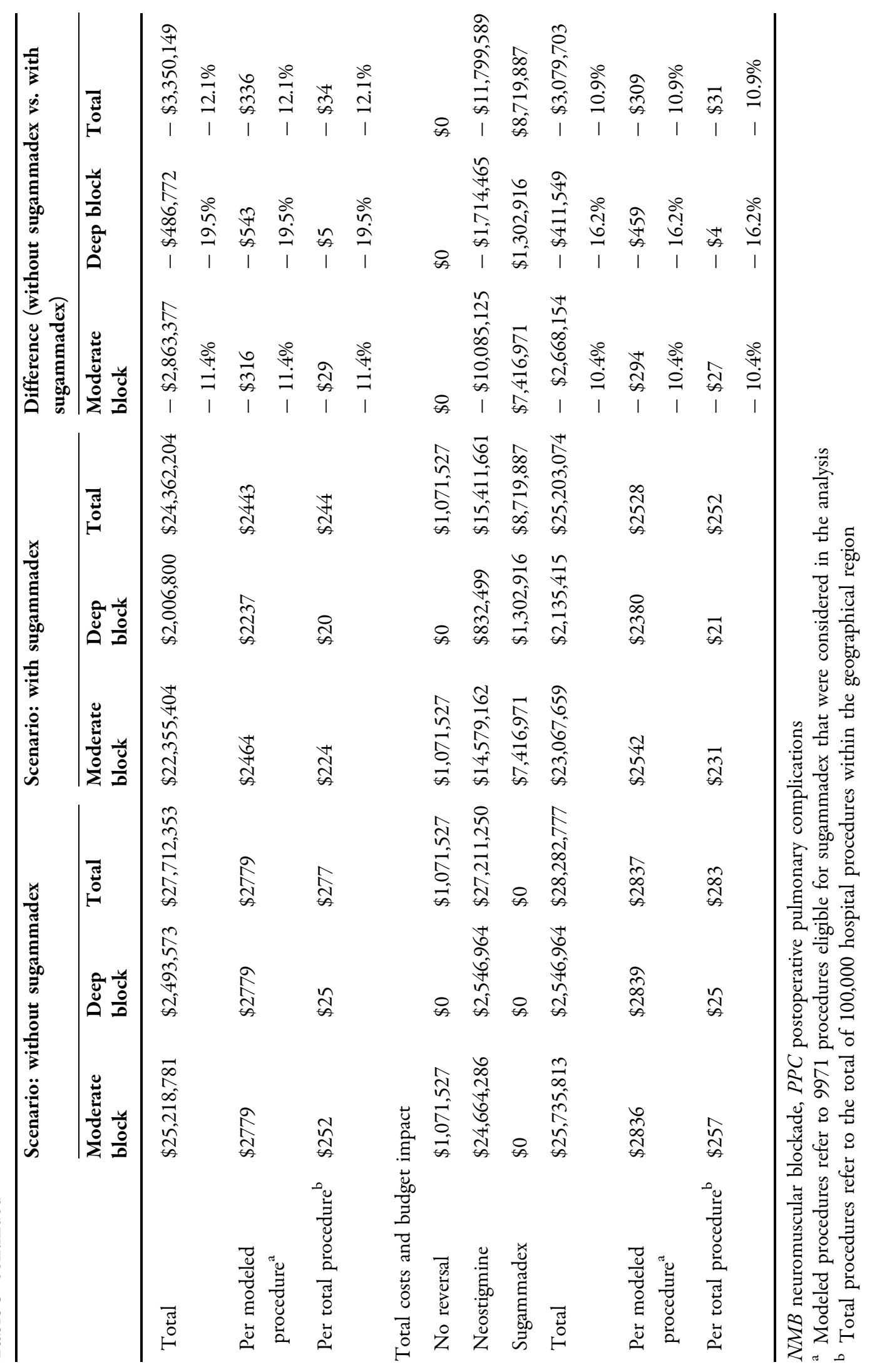




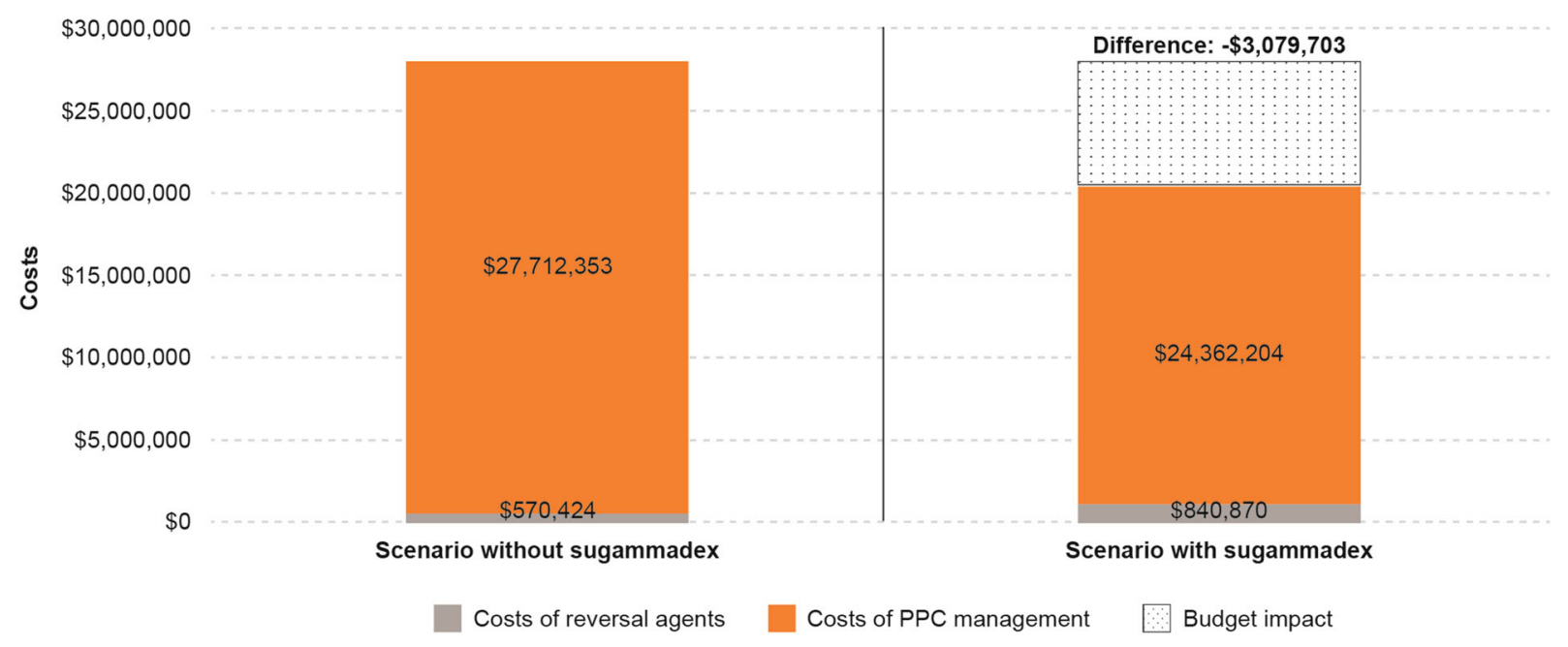

Fig. 2 Budget impact. $N M B$ neuromuscular blockade, $P P C$ postoperative pulmonary complications

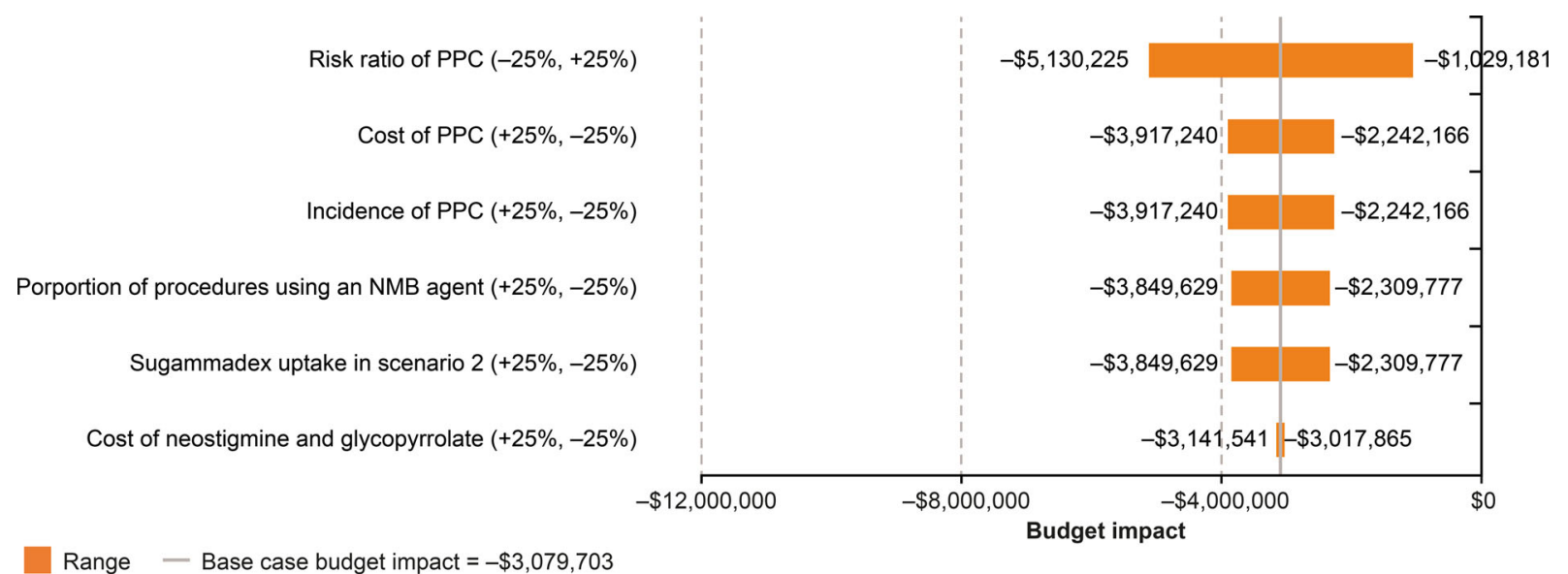

Fig. 3 Tornado diagram of one-way sensitivity analysis results. $N M B$ neuromuscular blockade, PPC postoperative pulmonary complications

approximately $19 \%(18,957)$ of these procedures used NMB. Of these, an estimated 9971 surgeries that utilized rocuronium or vecuronium resulting in moderate $(91.0 \%)$ or deep blockade $(9.0 \%)$ at the end of the procedure were considered in the model. In the without sugammadex scenario, it was assumed that $100 \%$ and $95.8 \%$ of patients with deep and moderate $\mathrm{NMB}$ at the end of the surgery, respectively, would receive neostigmine for NMB reversal (neostigmine use in 9585 cases overall; Fig. 1). In the with sugammadex scenario, sugammadex was expected to replace neostigmine in 4157 (41.7\%) procedures (Fig. 1).

\section{Number of PPC Events}

In the with sugammadex scenario, the use of sugammadex in 4156 of 9971 procedures was expected to result in 58 fewer cases of PPC events (12.1\% decrease) (Table 3) versus the without sugammadex scenario for moderate and deep block procedures in aggregate.

\section{Costs of Reversal Agents}

For the scenario without sugammadex, the total cost of reversal agents was estimated to be $\$ 570,424$ for the 9971 procedures, increasing to $\$ 840,870$ for the scenario with sugammadex 
(Table 3). Thus, the with sugammadex scenario was estimated to increase the total cost of reversal agents by $\$ 270,446$ for moderate and deep NMB procedures in aggregate, corresponding to an increase of $47.4 \%$ of the total costs of reversal agents. Of the 9971 procedures eligible to use sugammadex, the increase in cost was $\$ 27$ per modeled procedure (Table 3 ). The difference in reversal agent costs per any procedure in the geographical area (i.e., 100,000) was $\$ 3$.

\section{Costs of PPC Management}

In the with sugammadex scenario versus the without sugammadex scenario, for moderate and deep NMB procedures in aggregate, there was expected to be a reduction in the total cost of PPC management of $\$ 3,350,149$ (12.1\%). This corresponded to a reduction of $\$ 336$ per modeled procedure and a reduction of $\$ 34$ per total procedure (Table 3 ).

\section{Total Costs and Budget Impact}

The net total costs of reversing moderate and deep NMB procedures in aggregate, including the costs of respective PPC outcomes, was $\$ 28,282,777$ for the scenario without sugammadex and $\$ 25,203,074$ for the scenario with sugammadex. Therefore, the budget impact of introducing sugammadex was estimated to be $-\$ 3,079,703$ (Table 3; Fig. 2), equating to - \$309 per modeled procedure and $-\$ 31$ per total procedure. This corresponded to a reduction of $10.9 \%$ in healthcare costs (costs of reversal agent and costs of PPC management) associated with sugammadex versus without sugammadex (Table 3).

\section{Sensitivity Analysis}

In the sensitivity analysis, the budget impact associated with the introduction of sugammadex varied quantitatively in the degree of net cost savings (Fig. 3). The $\pm 25 \%$ variation in the risk ratio of PPC $(-25 \%$ to $+25 \%)$ for sugammadex versus neostigmine parameters resulted in the greatest change on the budget impact $(-5,130,225$ to $-\$ 1,029,181)$, followed by costs of PPC management $(+25 \%$ to $-25 \%$; $-\$ 3,917,240$ to $-\$ 2,242,166)$, incidence of
$\mathrm{PPC} \quad(+25 \%$ to $-25 \% ; \quad-\$ 3,849,629$ to $-\$ 2,309,777)$, proportion of procedures using an NMB agent $(+25 \%$ to $-25 \% ;-\$ 3,849,629$ to $-\$ 2,309,777)$, sugammadex uptake rate in the scenario with sugammadex (+25\% to $-25 \%$; $-\$ 3,849,629$ to $-\$ 2,309,777)$, and costs of neostigmine and glycopyrrolate $(+25 \%$ to $-25 \% ;-\$ 3,141,541$ to $-\$ 3,017,865)$. However, the variations to the variables did not result in qualitative changes to the budget impact as each variation continued to demonstrate cost savings with the increased use of sugammadex.

\section{DISCUSSION}

With continuously rising healthcare costs in the US, of which costs for hospital care account for $32.7 \%$ of the healthcare system [41], any new treatment or intervention for perioperative use is evaluated not only on its clinical benefits but also on its wide economic impact. In the anesthesia setting in particular, the need for health economic data to inform optimal treatment practices has been raised [42], in acknowledging concerns to minimize costs associated with NMB reversal [43]. As such, a better understanding of the sum of the impacts of NMB reversal usage may support formulary adoption and guide treatment management [25]. The present budget impact analysis points to substantial clinical cost offsets associated with the use of sugammadex for NMB reversal in the US.

Practices vary for achieving appropriate NMB reversal prior to extubation. Residual NMB, and the various adverse clinical consequences thereof, are key factors for evaluating the clinical value of reversal agents [6, 31, 44]. A large body of evidence from clinical trials [45-51] and observational studies (prospective $[6,52-54]$ and retrospective $[44,55])$ confirms that reversal with sugammadex significantly reduces the incidence of residual NMB in the post-anesthesia care unit, compared with neostigmine. Further, real-world data demonstrate that sugammadex administration is subsequently associated with reduced PPC $[17,29,54,56]$, on which the current analysis is based [17]. While some studies come to similar conclusions $[29,30,54,56,57]$, others come to different 
conclusions [57-61]. These studies were not considered to be appropriate for this analysis because they met one or more of the following exclusion criteria: reflected different practice in either a randomized controlled trial (measuring efficacy not effectiveness) or ex-US settings, were underpowered to detect a difference in treatment groups, were less representative (e.g., reflected a single site practice), or assessed different outcomes. Had these studies been considered, the model evaluated in this resource would be less reflective of routine care in the US setting and estimated cost offsets would vary, depending on endpoints incorporated $[29,30,54,56-58,60,61]$.

This budget impact analysis has translated the evidence of clinical benefit of sugammadex into terms of broader economic value. The use of sugammadex in $41.7 \%$ of patients instead of neostigmine could potentially reduce $12.1 \%$ of PPC events. In this case, although the total cost of reversal agents would increase by $47.4 \%$ given the $41.7 \%$ displacement of neostigmine by sugammadex, this cost of reversal agents would be offset by the reduction in costs incurred in the management of PPC events; a $10.9 \%$ total budgetary saving from the healthcare payers' perspective. Based on a further analysis, switching from neostigmine to sugammadex can potentially lead to an average saving of $25.2 \%$ of the cost associated with reversal agents and PPC per patient. These results suggest substantial cost offsets associated with wider use of sugammadex for reversal of rocuronium- or vecuronium-induced NMB. Considering that the number needed to treat (sugammadex vs. neostigmine) to prevent one case of PPC is estimated at 76.2 [62], treatment of this number of patients with sugammadex would cost between $\$ 7600.19$ (assuming a 2 $\mathrm{mL}$ vial per patient) and \$13,921,74 (assuming a $5 \mathrm{~mL}$ vial per patient), substantially lower than the cost of managing a case of PPC $(\$ 57,902.69)$.

The main strengths of this study include the use of real-world data from a large, retrospective database analysis looking at PPC in almost 46,000 US patients [17], as well as analyzing PPC in patients undergoing surgery with NMB administration. In addition, the most recent US sources were used to obtain all the other parameters, enhancing the relevance of the study to the contemporary US hospital setting. Finally, the robustness of the results obtained from the analytic model was confirmed by the sensitivity analyses.

\section{Limitations}

Data on additional clinical outcomes were unavailable for the present study, and the full clinical benefits of sugammadex, as well as the potential for further cost savings, may not have been demonstrated. For example, rocuroniuminduced $\mathrm{NMB}$ is reversed $3-18$ times more quickly with sugammadex than neostigmine $[20,45,46,49]$, and 69 times more quickly with sugammadex versus spontaneous recovery from NMB [63]. Studies have also demonstrated that sugammadex allows earlier discharge from the operating room and therefore shorter length of stay [51, 64, 65], which increases efficiency and may be associated with some cost reductions. However, this was not considered in this study as some efficiency gains might have been captured by the cost of PPC, and their inclusion could lead to double counting. Similarly, other costs of postoperative care, beyond costs related to PPC, were not considered. A recent metaanalysis of 31 trials confirmed improved postoperative outcomes of sugammadex compared with neostigmine, with up to $40 \%$ fewer composite postoperative events, including bradycardia and postoperative nausea and vomiting, as well as overall signs of postoperative residual paralysis [21]. In addition, neostigmine has been associated with an increased risk of oxygen desaturation in the early postoperative period $[9,66]$, possibly attributable to inappropriate use, with attempts to reverse deep blockade or to high doses used inappropriately for shallow $\mathrm{NMB}$, which are less efficient and often lead to less complete recovery [67]. Lastly, evidence also suggests that avoidance of PPC [68] and the use of sugammadex [69] may lead to lower mortality after non-cardiac surgeries. However, as the focus of the analysis was short-term budgetary impact, these potential benefits were not captured by the current study. Thus, the findings of the present analysis could be viewed 
as being conservative without consideration of these additional health economic impacts.

The analysis did not consider the impact of anaphylaxis on the results. In the product label of sugammadex, the incidence of anaphylaxis is reported at $0.3 \%$ ( 1 in 299 healthy volunteers; $16 \mathrm{mg} / \mathrm{kg}$ dose, only for NMB reversal soon after administration of a single dose of rocuronium) from a randomized clinical trial [32] in which participants were actively monitored. It is more rare in real-world settings, as passive surveillance, at far lower doses, across tens of millions of patient exposure has observed far fewer events [70-72], and its impact on the budget is likely to be negligible.

Given that the costs of clinical outcomes were based on HCUPnet data, which are national, bundled, diagnosis-related group (DRG)-like costs (to healthcare systems), it cannot be confirmed if the true costs of PPC management are reflected within the analysis. For example, the ICD diagnosis codes may be due to many other conditions and to the severity of clinical outcomes. Patient characteristics, including factors such as age, weight, and comorbidities, were not accounted for, and this may have also influenced the findings. Similarly, wholesale acquisition costs of reversal agents may not reflect the true costs that hospitals pay.

The present study assumes national rates of procedures using NMB and market shares of NMBAs and reversal agents, based on unpublished data and surveys, due to a lack of published information. NMB and NMB reversal practice may vary by patient, procedure, and provider, with significant variability within the US and across countries, as evidenced by the lack of international guidelines [73-76]. Hence, the findings need to be interpreted with care for smaller geographical regions, potential temporal change in these estimates, and varying local practice [74]. Clinical outcomes and usage of reversal agents may be dependent on local practices and familiarity with reversal agents [74]. Costs associated with the management of PPC may also differ from region to region, and such costs should be adjusted to reflect local price levels. Similarly, the costs of reversal agents were estimated using the corresponding label-based doses, which might not reflect actual clinical practice.

As an economic model, the results from the analysis may not be applicable to individual hospitals or specific populations. While these results provide insights into the potential for cost offsets, they should be interpreted in conjunction with local practice, costs, and circumstances. Further external validation, especially generation of real-world data, is required to confirm these results generated by a theoretical economic model.

Finally, the results of this budget impact analysis may not be directly applicable for hospital decision-making since hospital budgets are calculated as the difference between income (e.g., payment by Medicare or private insurer based on DRGs) and the actual costs of healthcare activities, including hospital overheads [25]. To reflect this, a calculation of cost and reimbursement to the hospital for medications and PPC management is required, which was outside of the scope of the current analysis. Nonetheless, the results may be informative in helping to understand the potential indirect benefits related to incremental increases in direct costs, and offer initial observations for anesthesiologists and hospital decision-makers as they consider NMB management options.

\section{CONCLUSION}

The use of some products in the anesthesia setting may be prohibited by their high cost. In this study, we examined both the cost of drugs and cost offsets associated with introducing sugammadex in the postoperative setting. Our analysis suggests that the incremental cost of using sugammadex to reverse rocuronium- or vecuronium-induced $\mathrm{NMB}$, rather than reversal with neostigmine/glycopyrrolate, could be offset by improved outcomes associated with fewer PPCs.

\section{ACKNOWLEDGEMENTS}

Funding. This study and the journal's Rapid Service Fee were funded by Merck Sharp \& 
Dohme Corp., a subsidiary of Merck \& Co., Inc., Kenilworth, NJ, USA. The sponsors participated with the investigators in the design and conduct of the study, analysis of the data, and preparation of the manuscript.

Medical Writing and Editorial Assistance. Medical writing support was provided by Gauri Saal, MA Economics and Valerie Moss $\mathrm{PhD}, \mathrm{CMPP}^{\mathrm{TM}}$, of Scion, London, UK, and was funded by Merck Sharp \& Dohme Corp., a subsidiary of Merck \& Co., Inc., Kenilworth, NJ, USA.

Authorship. All named authors meet the International Committee of Medical Journal Editors (ICMJE) criteria for authorship for this article, take responsibility for the integrity of the work as a whole, and have given their approval for this version to be published.

Author Contributions. Yiling Jiang was responsible for acquisition and analysis of data. All authors have made substantial contributions to the conception and design of the work, interpretation of data, and have drafted the work or substantively revised it. All authors have read and approved the manuscript. All authors have agreed both to be personally accountable for the author's own contributions and to ensure that questions related to the accuracy or integrity of any part of the work, even ones in which the author was not personally involved, are appropriately investigated, resolved, and the resolution documented in the literature.

Disclosures. Yiling Jiang is an employee of Merck Sharp \& Dohme (UK) Ltd., a subsidiary of Merck \& Co., Inc., Kenilworth, NJ, USA, which manufactures and distributes sugammadex, and may own stock and/or hold stock options in the Company. Lori D. Bash is an employee of Merck Sharp \& Dohme Corp., a subsidiary of Merck \& Co., Inc., Kenilworth, NJ, USA, which manufactures and distributes sugammadex, and may own stock and/or hold stock options in the Company. Leif Saager reports grant support and consultant fees from Merck \& Co., Inc., Kenilworth, NJ, USA during the conduct of the study; grants, personal fees and non-financial support from Merck \& Co., Inc., Kenilworth, NJ, USA outside the submitted work; personal fees and non-financial support from Medtronic.

Compliance with Ethics Guidelines. This was a hypothetical modeling study with no real patients involved, and hence no ethics approval or consent was required or requested. Assumptions for the model were derived from existing published study data as referenced within the text.

Data Availability. All data generated or analyzed during this study are included in this published article.

Open Access. This article is licensed under a Creative Commons Attribution-NonCommercial 4.0 International License, which permits any non-commercial use, sharing, adaptation, distribution and reproduction in any medium or format, as long as you give appropriate credit to the original author(s) and the source, provide a link to the Creative Commons licence, and indicate if changes were made. The images or other third party material in this article are included in the article's Creative Commons licence, unless indicated otherwise in a credit line to the material. If material is not included in the article's Creative Commons licence and your intended use is not permitted by statutory regulation or exceeds the permitted use, you will need to obtain permission directly from the copyright holder. To view a copy of this licence, visit http://creativecommons.org/licenses/by$\mathrm{nc} / 4.0 /$.

\section{REFERENCES}

1. Robertson T, Ridge A. Proposal for update of the anaesthesia and muscle relaxant sections of the WHO; 18th Expert Committee on the Selection and Use of Essential Medicines. 2010. http://www.who. int/selection_medicines/committees/expert/18/ applications/anaesthetic_proposal.pdf. Accessed 10 July 2019.

2. Wilcox SR, Bittner EA, Elmer J, et al. Neuromuscular blocking agent administration for emergent 
tracheal intubation is associated with decreased prevalence of procedure-related complications. Crit Care Med. 2012;40:1808-13.

3. Murphy GS, Brull SJ. Residual neuromuscular block: lessons unlearned. Part I: definitions, incidence, and adverse physiologic effects of residual neuromuscular block. Anesth Analg. 2010;111:120-8.

4. Murphy GS. Residual neuromuscular blockade: incidence, assessment, and relevance in the postoperative period. Minerva Anestesiol. 2006;72: 97-109.

5. Belcher AW, Leung S, Cohen B, et al. Incidence of complications in the post-anesthesia care unit and associated healthcare utilization in patients undergoing non-cardiac surgery requiring neuromuscular blockade 2005-2013: a single center study. J Clin Anesth. 2017;43:33-8.

6. Saager L, Maiese EM, Bash LD, et al. Incidence, risk factors, and consequences of residual neuromuscular block in the United States: the prospective, observational, multicenter RECITE-US study. J Clin Anesth. 2019;55:33-41.

7. Yu B, Ouyang B, Ge S, et al. Incidence of postoperative residual neuromuscular blockade after general anesthesia: a prospective, multicenter, anesthetist-blind, observational study. Curr Med Res Opin. 2016;32:1-9.

8. Fortier LP, McKeen D, Turner K, et al. The RECITE study: a canadian prospective, multicenter study of the incidence and severity of residual neuromuscular blockade. Anesth Analg. 2015;121:366-72.

9. Grosse-Sundrup M, Henneman JP, Sandberg WS, et al. Intermediate acting non-depolarizing neuromuscular blocking agents and risk of postoperative respiratory complications: prospective propensity score matched cohort study. BMJ. 2012;345:e6329.

10. Bulka CM, Terekhov MA, Martin BJ, et al. Nondepolarizing neuromuscular blocking agents, reversal, and risk of postoperative pneumonia. Anesthesiology. 2016;125:647-55.

11. Butterly A, Bittner EA, George E, et al. Postoperative residual curarization from intermediate-acting neuromuscular blocking agents delays recovery room discharge $\uparrow$. Br J Anaesth. 2010;105:304-9.

12. Murphy GS, Szokol JW, Marymont JH, et al. Residual neuromuscular blockade and critical respiratory events in the postanesthesia care unit. Anesth Analg. 2008;107:130-7.

13. Bronsert MR, Henderson WG, Monk TG, et al. Intermediate-acting nondepolarizing neuromuscular blocking agents and risk of postoperative 30-day morbidity and mortality, and long-term survival. Anesth Analg. 2017;124:1476-83.

14. Kopman AF, Yee PS, Neuman GG. Relationship of the train-of-four fade ratio to clinical signs and symptoms of residual paralysis in awake volunteers. Anesthesiology. 1997;86:765-71.

15. Murphy GS, Szokol JW, Franklin $\mathrm{M}$, et al. Postanesthesia care unit recovery times and neuromuscular blocking drugs: a prospective study of orthopedic surgical patients randomized to receive pancuronium or rocuronium. Anesth Analg. 2004;98:193-200.

16. Grabitz SD, Rajaratnam N, Chhagani K, et al. The effects of postoperative residual neuromuscular blockade on hospital costs and intensive care unit admission: a population-based cohort study. Anesth Analg. 2019;128:1129-36.

17. Kheterpal S, Vaughn MT, Dubovoy TZ. Sugammadex versus neostigmine for reversal of neuromuscular blockade and postoperative pulmonary complications (STRONGER): A multicenter matched cohort analysis. Anesthesiology. 2020;132: 1371-81.

18. Bom A, Bradley M, Cameron K, et al. A novel concept of reversing neuromuscular block: chemical encapsulation of rocuronium bromide by a cyclodextrin-based synthetic host. Angew Chem Int Ed Engl. 2002;41:266-70.

19. Bom A, Epemolu O, Hope F, et al. Selective relaxant binding agents for reversal of neuromuscular blockade. Curr Opin Pharmacol. 2007;7:298-302.

20. Herring WJ, Woo T, Assaid CA, et al. Sugammadex efficacy for reversal of rocuronium- and vecuronium-induced neuromuscular blockade: a pooled analysis of 26 studies. J Clin Anesth. 2017;41:84-91.

21. Hristovska AM, Duch P, Allingstrup M, et al. Efficacy and safety of sugammadex versus neostigmine in reversing neuromuscular blockade in adults. Cochrane Database Syst Rev. 2017;8:CD012763.

22. Hristovska AM, Duch P, Allingstrup M, et al. The comparative efficacy and safety of sugammadex and neostigmine in reversing neuromuscular blockade in adults. A Cochrane systematic review with meta-analysis and trial sequential analysis. Anaesthesia. 2018;73:631-41.

23. Mihailovic N, Kocic S, Jakovljevic M. Review of diagnosis-related group-based financing of hospital care. Health Serv Res Manag Epidemiol. 2016;3: 2333392816647892-92.

24. Sullivan SD, Mauskopf JA, Augustovski F, et al. Budget impact analysis-principles of good practice: 
report of the ISPOR 2012 Budget Impact Analysis Good Practice II Task Force. Value Health. 2014;17: 5-14.

25. US Department of Veterans Affairs-Health Economics Resource Center (HERC). Budget impact analysis. https://www.herc.research.va.gov/ include/page.asp?id=budget-impact-analysis.

Accessed 4 Oct 2019.

26. FMCP Format Executive Committee. The AMCP format for formulary submissions version 3.0. J Manag Care Pharm. 2010;16:1-30.

27. Husereau D, Drummond M, Petrou S, et al. Consolidated health economic evaluation reporting standards (CHEERS) statement. BMC Med. 2013;11: 80 .

28. Jammer I, Wickboldt N, Sander M, et al. Standards for definitions and use of outcome measures for clinical effectiveness research in perioperative medicine: european Perioperative Clinical Outcome (EPCO) definitions: a statement from the ESAESICM joint taskforce on perioperative outcome measures. Eur J Anaesthesiol. 2015;32:88-105.

29. Krause M, McWilliams SK, Bullard KJ, et al. Neostigmine versus sugammadex for reversal of neuromuscular blockade and effects on reintubation for respiratory failure or newly initiated noninvasive ventilation: an interrupted time series design. Anesth Analg. 2020;131:141-51.

30. Moon TS, Reznik S, Pak T, et al. Sugammadex versus neostigmine for reversal of rocuronium-induced neuromuscular blockade: a randomized, doubleblinded study of thoracic surgical patients evaluating hypoxic episodes in the early postoperative period. J Clin Anesth. 2020;64:109804.

31. Fuchs-Buder T, Nemes R, Schmartz D. Residual neuromuscular blockade: management and impact on postoperative pulmonary outcome. Curr Opin Anaesthesiol. 2016;29:662-7.

32. Food and Drug Administration. Sugammadex injection-prescribing information. 2015. https:// www.accessdata.fda.gov/drugsatfda_docs/label/ 2015/022225lbl.pdf.

33. Fryar CD, Gu Q, Ogden CL, et al. Anthropometric reference data for children and adults: united States, 2011-2014. Vital Health Stat. 2016;3:1-46.

34. Food and Drug Administration. Neostigmine methylsulfate injection-prescribing information. 2013. https://www.accessdata.fda.gov/drugsatfda_ docs/label/2013/204078s000lbl.pdf.

35. Haerter F, Eikermann M. Reversing neuromuscular blockade: inhibitors of the acetylcholinesterase versus the encapsulating agents sugammadex and calabadion. Expert Opin Pharmaco. 2016;17: 819-33.

36. Monk TG, Rietbergen H, Woo T, et al. Use of sugammadex in patients with obesity: a pooled analysis. Am J Ther. 2017;24:e507-16.

37. Horrow J, Li W, Blobner M, et al., editors. Actual versus ideal body weight dosing of sugammadex in the morbidly obese. Anesthesiology; 2019; Orlando, FL, USA.

38. AnalySource. AnalySource ${ }^{\circledR}$ : premier access to the First Databank drug pricing database. https://www. analysource.com/. Accessed 8 Oct 2019.

39. Agency for Healthcare Research and Quality. HCUPnet healthcare cost and utilization project. 2015. https://hcupnet.ahrq.gov/\#setup. Accessed 15 July 2019.

40. Bureau of Labor Statistics USDoL. Consumer Price Index, May 2019. 2019. https://www.bls.gov/cpi/. Accessed 24 May 2019.

41. American Medical Association. Policy research perspectives-national health expenditures, 2017. 2019. https://www.ama-assn.org/system/files/201904/prp-annual-spending-2017.pdf. Accessed 14 Nov 2019.

42. de Boer HD, Carlos RV, Brull SJ. Is lower-dose sugammadex a cost-saving strategy for reversal of deep neuromuscular block? Facts and fiction. BMC Anesthesiol. 2018;18:159.

43. Aouad MT, Alfahel WS, Kaddoum RN, et al. Half dose sugammadex combined with neostigmine is non-inferior to full dose sugammadex for reversal of rocuronium-induced deep neuromuscular blockade: a cost-saving strategy. BMC Anesthesiol. 2017;17:57.

44. Domenech G, Kampel MA, García Guzzo ME, et al. Usefulness of intra-operative neuromuscular blockade monitoring and reversal agents for postoperative residual neuromuscular blockade: a retrospective observational study. BMC Anesthesiol. 2019;19:143.

45. Jones RK, Caldwell JE, Brull SJ, et al. Reversal of profound rocuronium-induced blockade with sugammadex: a randomized comparison with neostigmine. Anesthesiology. 2008;109:816-24.

46. Blobner M, Eriksson LI, Scholz J, et al. Reversal of rocuronium-induced neuromuscular blockade with sugammadex compared with neostigmine during sevoflurane anaesthesia: results of a randomised, controlled trial. Eur J Anaesthesiol. 2010;27:874-81. 
47. Khuenl-Brady KS, Wattwil M, Vanacker BF, et al. Sugammadex provides faster reversal of vecuronium-induced neuromuscular blockade compared with neostigmine: a multicenter, randomized, controlled trial. Anesth Analg. 2010;110:64-73.

48. Lemmens HJ, El-Orbany MI, Berry J, et al. Reversal of profound vecuronium-induced neuromuscular block under sevoflurane anesthesia: sugammadex versus neostigmine. BMC Anesthesiol. 2010;10:15.

49. Geldner G, Niskanen M, Laurila P, et al. A randomised controlled trial comparing sugammadex and neostigmine at different depths of neuromuscular blockade in patients undergoing laparoscopic surgery. Anaesthesia. 2012;67:991-8.

50. Rahe-Meyer N, Berger C, Wittmann $M$, et al. Recovery from prolonged deep rocuronium-induced neuromuscular blockade: a randomized comparison of sugammadex reversal with spontaneous recovery. Anaesthesist. 2015;64:506-12.

51. Brueckmann B, Sasaki N, Grobara P, et al. Effects of sugammadex on incidence of postoperative residual neuromuscular blockade: a randomized, controlled study. Br J Anaesth. 2015;115:743-51.

52. Errando CL, Garutti I, Mazzinari G, et al. Residual neuromuscular blockade in the postanesthesia care unit: observational cross-sectional study of a multicenter cohort. Minerva Anestesiol. 2016;82: 1267-77.

53. Raval AD, Uyei J, Karabis A, et al. Incidence of residual neuromuscular blockade and use of neuromuscular blocking agents with or without antagonists: a systematic review and meta-analysis of randomized controlled trials. J Clin Anesth. 2020;64:109818.

54. Martinez-Ubieto J, Ortega-Lucea S, Pascual-Bellosta A, et al. Prospective study of residual neuromuscular block and postoperative respiratory complications in patients reversed with neostigmine versus sugammadex. Minerva Anestesiol. 2016;82:735-42.

55. Raval AD, Anupindi VR, Ferrufino CP, et al. Epidemiology and outcomes of residual neuromuscular blockade: a systematic review of observational studies. J Clin Anesth. 2020;66:109962.

56. Evron S, Abelansky Y, Ezri T, et al. Respiratory events with sugammadex vs. neostigmine following laparoscopic sleeve gastrectomy: a prospective pilot study assessing neuromuscular reversal strategies. Rom J Anaesth Intensive Care. 2017;24:111-14.

57. Kirmeier E, Eriksson LI, Lewald H, et al. Postanaesthesia pulmonary complications after use of muscle relaxants (POPULAR): a multicentre, prospective observational study. Lancet Respir Med. 2019;7:129-40.

58. Alday E, Muñoz M, Planas A, et al. Effects of neuromuscular block reversal with sugammadex versus neostigmine on postoperative respiratory outcomes after major abdominal surgery: a randomized-controlled trial. Can J Anaesth. 2019;66:1328-37.

59. Chae YJ, Joe HB, Oh J, et al. Thirty-day postoperative outcomes following sugammadex use in colorectal surgery patients; retrospective study. J Clin Med. 2019;8:97.

60. Ezri T, Evron S, Petrov I, et al. Residual curarization and postoperative respiratory complications following laparoscopic sleeve gastrectomy. The effect of reversal agents: sugammadex vs. neostigmine. J Crit Care Med (Targu Mures). 2015;1:61-67.

61. Togioka BM, Yanez D, Aziz MF, et al. Randomised controlled trial of sugammadex or neostigmine for reversal of neuromuscular block on the incidence of pulmonary complications in older adults undergoing prolonged surgery. Br J Anaesth. 2020;124: 553-61.

62. Bash LD, Vaughn MT, Jiang Y, et al. Reducing pulmonary complications after surgery in patients receiving reversal of neuromuscular blockade: analysis from the multicenter perioperative outcomes group. Abstract Poster Reception Networking Event, ACS NSQIP Adult Research presented at: ACS Quality and Safety Conference 2019; July 19-22, 2019; Washington, DC, U.S.A. 2019.

63. Puhringer FK, Rex C, Sielenkamper AW, et al. Reversal of profound, high-dose rocuronium-induced neuromuscular blockade by sugammadex at two different time points: an international, multicenter, randomized, dose-finding, safety assessor-blinded, phase II trial. Anesthesiology. 2008;109:188-97.

64. Insinga RP, Joyal $\mathrm{C}$, Goyette $\mathrm{A}$, et al. A discrete event simulation model of clinical and operating room efficiency outcomes of sugammadex versus neostigmine for neuromuscular block reversal in Canada. BMC Anesthesiol. 2016;16:114.

65. Marti FS, G; Mauch J. Economic considerations for the use of Sugammadex in a Swiss Department of Anaesthesiology. Anästh Intensivmed. 2017;58: 325-29.

66. Meyer MJ, Bateman BT, Kurth T, et al. Neostigmine reversal doesn't improve postoperative respiratory safety. BMJ. 2013;346:f1460.

67. Fuchs-Buder T. Neostigmine: timing and dosing in 2016. Anaesth Crit Care Pain Med. 2016;35:245-7. 
68. Fernandez-Bustamante A, Frendl G, Sprung J, et al. Postoperative pulmonary complications, early mortality, and hospital stay following noncardiothoracic surgery: a multicenter study by the Perioperative Research Network Investigators. JAMA Surg. 2017;152:157-66.

69. Oh TK, Ryu JH, Nam S, et al. Association of neuromuscular reversal by sugammadex and neostigmine with 90-day mortality after non-cardiac surgery. BMC Anesthesiol. 2020;20:41.

70. Burbridge MA. Incidence of anaphylaxis to sugammadex in a single-center cohort of 19,821 patients. Anesth Analg. 2021;132:93-7.

71. Orihara M, Takazawa T, Horiuchi T, et al. Comparison of incidence of anaphylaxis between sugammadex and neostigmine: a retrospective multicentre observational study. $\mathrm{Br} \mathrm{J}$ Anaesth. 2020;124:154-63.

72. Miyazaki Y, Sunaga $H$, Kida K, et al. Incidence of anaphylaxis associated with sugammadex. Anesth Analg. 2018;126:1505-8.
73. Batistaki C, Vagdatli K, Tsiotou A, et al. A multicenter survey on the use of neuromuscular blockade in Greece. Does the real-world clinical practice indicate the necessity of guidelines? J Anaesthesiol Clin Pharmacol. 2019;35:202-14.

74. Naguib M, Kopman AF, Lien CA, et al. A survey of current management of neuromuscular block in the United States and Europe. Anesth Analg. 2010;111: 110-9.

75. Pongracz A, Nemes R, Breazu C, et al. International survey of neuromuscular monitoring in two European countries: a questionnaire study among Hungarian and Romanian anaesthesiologists. Rom J Anaesth Intensive Care. 2019;26:45-51.

76. Dubovoy TZ, Saager L, Shah NJ, et al. Utilization patterns of perioperative neuromuscular blockade reversal in the united states: a retrospective observational study from the multicenter perioperative outcomes group. Anesth Analg. 2020;131:1510-9. 